Article

\title{
Genome-Wide Identification, Characterization and Expression Analysis of the Chalcone Synthase Family in Maize
}

\author{
Yahui Han ${ }^{\dagger}$, Ting Ding ${ }^{\dagger}$, Bo Su and Haiyang Jiang * \\ Key Laboratory of Crop Biology of Anhui Province, Anhui Agricultural University, Hefei 230036, China; \\ hyahui@163.com (Y.H.); dingting98@126.com (T.D.); subo315@163.com (B.S.) \\ * Correspondence: hyjiang@ahau.edu.cn; Tel.: +86-551-6578-6423; Fax: +86-551-6578-6021 \\ + These authors contributed equally to this work.
}

Academic Editor: Marcello Iriti

Received: 24 October 2015; Accepted: 19 January 2016; Published: 27 January 2016

\begin{abstract}
Members of the chalcone synthase (CHS) family participate in the synthesis of a series of secondary metabolites in plants, fungi and bacteria. The metabolites play important roles in protecting land plants against various environmental stresses during the evolutionary process. Our research was conducted on comprehensive investigation of CHS genes in maize (Zea mays L.), including their phylogenetic relationships, gene structures, chromosomal locations and expression analysis. Fourteen CHS genes (ZmCHS01-14) were identified in the genome of maize, representing one of the largest numbers of $\mathrm{CHS}$ family members identified in one organism to date. The gene family was classified into four major classes (classes I-IV) based on their phylogenetic relationships. Most of them contained two exons and one intron. The 14 genes were unevenly located on six chromosomes. Two segmental duplication events were identified, which might contribute to the expansion of the maize CHS gene family to some extent. In addition, quantitative real-time PCR and microarray data analyses suggested that $\mathrm{ZmCHS}$ genes exhibited various expression patterns, indicating functional diversification of the $\mathrm{ZmCHS}$ genes. Our results will contribute to future studies of the complexity of the CHS gene family in maize and provide valuable information for the systematic analysis of the functions of the CHS gene family.
\end{abstract}

Keywords: chalcone synthase; genome-wide analysis; expression; evolution; maize

\section{Introduction}

Chalcone synthase (CHS, enzyme commission number: E.C. 2.3.1.74) is an important enzyme which catalyzes the first key step during the progress of flavonoid biosynthesis. CHS condenses three acetate units of malonyl-coenzyme A (malonyl-CoA) with a phenylpropanoid CoA ester ( $p$-coumaroyl-CoA) to generate a chalcone, which is the precursor of various flavonoids [1]. Recent studies about the CHS gene family indicated that generation and loss of genes frequently occurred, and that $\mathrm{CHS}$ and non-CHS genes had co-evolved throughout the evolutionary process of angiosperms [2]. The enzyme family is also known as type III polyketide synthases [3], which exist in all the plant species. Members of the CHS family are homodimers of 40-45 kDa subunits, and possess a Cys-His-Asn catalytic triad $(\mathrm{CHN})$ in their active sites [2]. They show similarity in sequences, structures and catalytic principles [3,4]. CHS is a representative of the CHS family. This family also includes other members such as biphenyl synthase [5], 2-pyrone synthase (2-PS) [6], benzalacetone synthase [7], stilbene synthase [8], bibenzyl synthase [9], benzophenone synthase [10], pentaketide chromone synthase [11], octaketide synthase [12] and $p$-coumaroyltriacetic acid synthase [13]. All these other enzymes have differences from CHS in many aspects, such as the choice of initial substrates, the number 
of condensation reactions, and the mechanisms by which the resulting intermediates are cyclized and aromatized. Stilbene synthase (STS), which was identified in pines and peanuts, exhibits an identity of $>65 \%$ with CHS protein sequences and also condenses three acetate units of malonyl-CoA with a phenylpropanoid CoA ester. Unlike CHS, STS cyclizes the intermediate by another pathway, in which $\mathrm{CO}_{2}$ is lost to generate resveratrol, a phytoalexin stilbene. By contrast, 2-PS in gerbera condenses acetyl-CoA with two malonyl-CoA to generate a pyrone, which is converted into antifeedant glucoside metabolites [14]. Therefore, the CHS family together participates in the biosyntheses of various natural products, which play significant roles in flower pigmentation, pollen fertility and protection against UV. CHS genes have been widely studied because of their important functions. A number of aspects on regulation and function of $\mathrm{CHS}$ family have been investigated in many plants, including grape [15], Gerbera hybrida [16], apple [17], Oncidium orchid [18], Hypericum sampsonii [10], Arabidopsis [19], Petunia [20] and bean [21]. Two maize CHS genes were previously reported, C2 and Whp [22,23]. Moreover, one anther specific chalcone synthase-like (ASCL) gene (ZmCHSL, NP_001149508) was also reported by Jepson et al. [24]. Products of 15 or even more genes are essential for anthocyanin biosynthesis in maize [25], including $C H S$ gene $C 2$, which probably have a bearing on the production of the anthocyanin pigment $[26,27]$. The CHS family had also been studied comprehensively in Physcomitrella patens [28].

Recently, the whole genome assembly of maize (Zea mays L. B73) has been completed [29], which made it possible to perform a genome-wide investigation of the CHS family to analyze their evolutionary processes and functional diversification in this species. In our study, we carried out an overall analysis of the CHS family by searching the whole genome of maize. Furthermore, many studies reported that the expression of $\mathrm{CHS}$ genes in different plants was induced by a number of biotic and abiotic stress responses [30]. In this study, $\mathrm{ZmCHS}$ transcripts were measured and showed enhanced expression after salicylic acid (SA) treatment. Results of this study will provide a new start for the future studies of the functional diversification and evolutionary process of the CHS family in angiosperms.

\section{Results}

\subsection{Identification and Annotation of Chalcone Synthase (CHS) Genes in Maize}

Sixty-five candidate CHS protein sequences were identified by querying the maize genome database with the consensus protein sequences of the CHS family. Whereafter, all candidate CHS proteins were investigated for the presence of the Chal_sti_synt_C (PF02797) and Chal_sti_synt_N (PF00195) domains by searching Pfam Datebase [31]. The two domains were predicted to possess molecular function of transferase activity and transferring acyl groups (GO:0016746) according to Gene Ontology [32]. In addition, Chal_sti_synt_N domain possess molecular function of biological process biosynthetic process (GO:0009058). Finally, fifty-one protein sequences were discarded because they lacked the two domains or represented overlapping genes, and 14 non-redundant $C H S$ genes (named ZmCHS01-14) were identified and described (Table 1).

Table 1. The chalcone synthase family genes of maize.

\begin{tabular}{ccccccc}
\hline Number & Gene Name & Translation Product & Mw (Da) & Size (aa) & pI & Chromosome \\
\hline 1 & ZmCHS01 & GRMZM2G422750_P03 & 43195.59 & 400 & 6.33 & 4 \\
2 & ZmCHSO2 & GRMZM2G151227_P01 & 43325.61 & 401 & 6.02 & 2 \\
3 & ZmCHSO3 & GRMZM2G175812_P01 & 43006.2 & 402 & 5.74 & 7 \\
4 & ZmCHSO4 & AC191551.3_FGP03 & 43065.52 & 396 & 5.98 & 3 \\
6 & ZmCHSO5 & GRMZM2G435393_P01 & 43425.83 & 398 & 6.28 & 3 \\
7 & ZmCHSO6 & GRMZM2G346095_P01 & 42391.54 & 397 & 6.19 & 5 \\
8 & ZmCHS07 & GRMZM2G009348_P01 & 49692.84 & 472 & 8.9 & 4 \\
\hline
\end{tabular}


Table 1. Cont.

\begin{tabular}{ccccccc}
\hline Number & Gene Name & Translation Product & Mw (Da) & Size (aa) & pI & Chromosome \\
\hline 9 & ZmCHS08 & GRMZM2G009510_P01 & 44829.17 & 420 & 6.08 & 4 \\
10 & ZmCHS09 & GRMZM2G027130_P01 & 44136.6 & 420 & 5.83 & 2 \\
11 & ZmCHS10 & GRMZM2G114471_P01 & 43556.78 & 405 & 5.46 & 4 \\
12 & ZmCHS11 & GRMZM2G108894_P01 & 45994.51 & 427 & 5.35 & 7 \\
13 & ZmCHS12 & GRMZM2G131529_P01 & 35275.5 & 326 & 5.77 & 3 \\
14 & ZmCHS13 & GRMZM2G477683_P01 & 45574.27 & 421 & 8.08 & 5 \\
15 & ZmCHS14 & GRMZM2G380650_P02 & 42110.41 & 390 & 6.92 & 1 \\
\hline
\end{tabular}

Mw: molecular mass; pI: isoelectric point.

\subsection{Phylogenetic and Structural Analysis of the Putative Maize CHS Proteins}

An unrooted phylogenetic tree (Figure 1) was generated by multiple sequence alignment of the protein sequences of all the $\mathrm{ZmCHS}$ genes. The $\mathrm{ZmCHS}$ genes were classified into four major groups (classes I, II, III and IV) based on the phylogenetic tree, with supported bootstrap values. Subsequently, gene structure (including exons and introns) analysis was done to support the phylogenetic analysis. Additional sequence alignment analysis was conducted to reveal the genetic relationship between the $14 \mathrm{ZmCHSs}$ and C2, Whp and ZmCHSL [22-24]. The three gene pairs (ZmCHS01-C2, ZmCHSO2-Whp, $\mathrm{ZmCHS11-ZmCHSL}$ ) showed high identities of $100 \%, 96.76 \%$ and $97.66 \%$ respectively in their sequence alignment. Therefore, we confirmed that $\mathrm{ZmCHSO1}$ is $\mathrm{C2}$, and $\mathrm{ZmCHSO2}$ and $\mathrm{ZmCHS11}$ are likely to be Whp and $\mathrm{ZmCHSL}$, respectively. The schematic structures revealed that most $\mathrm{ZmCHS}$ genes exhibited similar gene structures, two exons and one intron. While $\mathrm{ZmCHS12}$ contained only one exon, and $\mathrm{ZmCHS10} \mathrm{had} \mathrm{multiple} \mathrm{exons} \mathrm{and} \mathrm{introns.}$

A

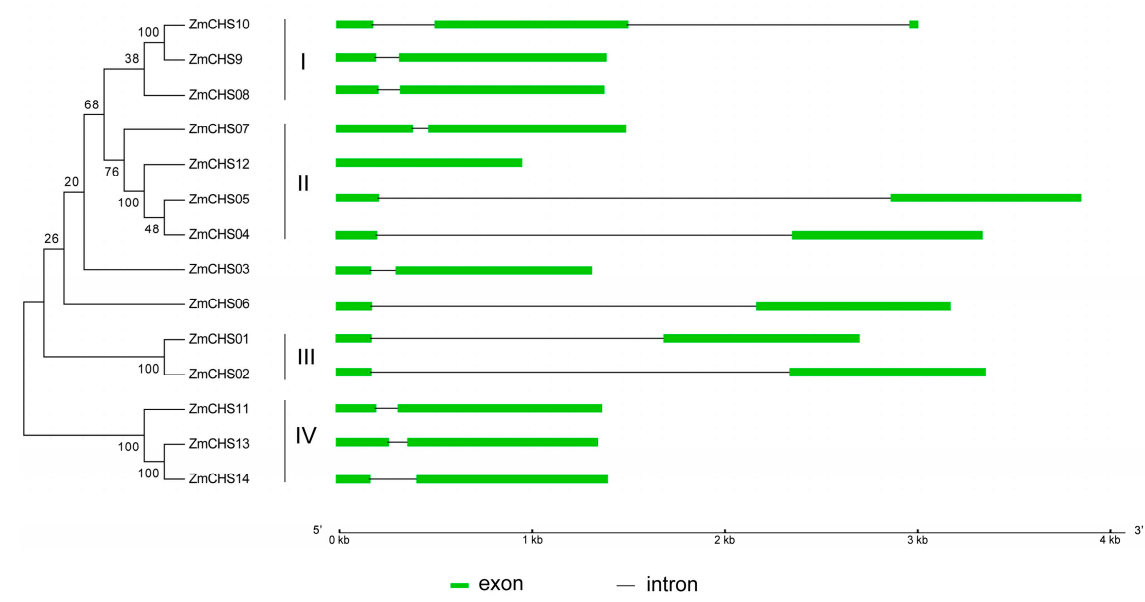

Figure 1. Phylogenetic tree and gene structure of the 14 predicted maize chalcone synthases (CHSs). (A) The unrooted neighbor-joining tree was constructed using the MEGA4.0 program. The bootstrap values, which were produced using 1000 replicates with the pairwise deletion option, are noted at each node; (B) Exon-intron structure was generated using Gene Structure Display Server (GSDS). The exons and introns are indicated by green boxes and gray lines, respectively. The scale at the bottom is in kilobases.

\subsection{Conserved Motifs of the Putative ZmCHS Proteins and Sequence Alignment against Other Plant CHSs}

PTwenty conserved motifs were investigated in the putative CHS proteins of maize (Figure 2). The detailed information of the 20 motifs is listed in Table 2 and also shown in Figure 2. We categorized the 14 ZmCHSs into four classes (Figure 2) according to their phylogenetic relationships. The Chal_sti_synt_C 
domain was represented by motifs 1 and 8 . And the Chal_sti_synt_N domain was represented by motifs 2, 3, 4, 5, 6 and 9 (Table 2). The two domains were highly conserved in almost all of the putative ZmCHS proteins, except that ZmCHS12 lacks part of the Chal_sti_synt_N domain. Motifs 4 and 1 contained Cys164 and His303 and Asn336 respectively of the characteristic catalytic triad (Figure 2, Figure 3 and Table 2). The catalytic triad inherited from the ketoacyl synthase III (KAS III) ancestor [3] is also highly conserved in all of the ZmCHSs (Figure 3). In addition, many motifs were conserved within a subfamily. For example, motif 16 was present in all members of class II. All members of class IV contained conserved motifs 12 and 19. The subfamily-specific motifs might be required for subfamily-specific functions. However, some motifs (motif $1,2,4,5,6,7,8,10,11$ ) are distributed in every subfamily. So these motifs might be important for the functions of $\mathrm{ZmCHS}$ proteins.

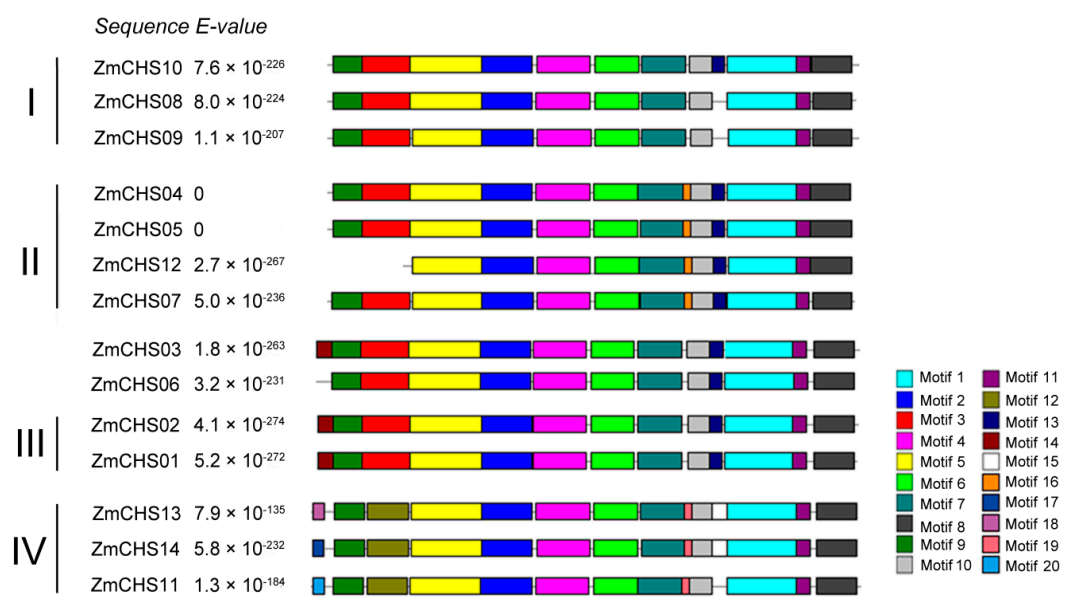

Figure 2. Distribution of 20 conserved motifs in the putative CHS proteins of maize. Motifs in the putative ZmCHS proteins were obtained using the Multiple Em for Motif Elicitation (MEME) web server. The length of each box does not represent the actual size of each motif.

Table 2. Detailed information of the 20 motifs in the putative maize chalcone synthase (CHS) proteins.

\begin{tabular}{|c|c|c|c|}
\hline Motif & Width & Best Possible Match & Domain \\
\hline 1 & 50 & WNDLFWAVHPGGPAILDQVEACLKLQPHKLKASRHVLSEYGNMSSPTVIF & Chal_sti_synt_C \\
\hline 2 & 36 & EWGRPATDITHLVFCTYSGAHMPGVDWQLASLLGLR & Chal_sti_synt_N \\
\hline 3 & 34 & NCVYQDEYPDYYFRITKSEHLTDLKEKFKRICHK & Chal_sti_synt_N \\
\hline 4 & 38 & RTMLYMNGCSGGCAALRVAKDMAENNRGARVLVACAEM & Chal_sti_synt_N \\
\hline 5 & 50 & IKKRYFHHTEELLREHPEFIDYSMPSLHERQDIMNSAVPELAAAAAQKAI & Chal_sti_synt_N \\
\hline 6 & 31 & FRPPHEDHPYTLIGQALFGDGAGAVIVGADP & Chal_sti_synt_N \\
\hline 7 & 31 & VERPIFEMVSASQTMIPDSEHVIDGQLCEDG & * \\
\hline 8 & 28 & CEWGVMVGFGPGFTVETMVLHACKKTKK & Chal_sti_synt_C \\
\hline 9 & 21 & RKWQRADGPATVLAIGTANPP & Chal_sti_synt_N \\
\hline 10 & 15 & REIPSLIEENIEQCM & $*$ \\
\hline 11 & 9 & VLDELRRRQ & * \\
\hline 12 & 29 & PQEKVVDSYLQESSCDDPDTRAKLQRLCT & * \\
\hline 13 & 8 & DAFSPLGI & * \\
\hline 14 & 11 & MAGATVTVEEV & * \\
\hline 15 & 11 & RTLMNKVGIKD & * \\
\hline 16 & 6 & LHFNPS & * \\
\hline 17 & 6 & IDQFIN & * \\
\hline 18 & 6 & VQHWKK & * \\
\hline 19 & 6 & INFKLG & * \\
\hline 20 & 7 & QIEYSCF & * \\
\hline
\end{tabular}

The detailed information of the 20 motifs are shown in the table, including their width, best possible match sequences, and domains they are contained in; *: represents the motifs that are not included in the domain sequences. 

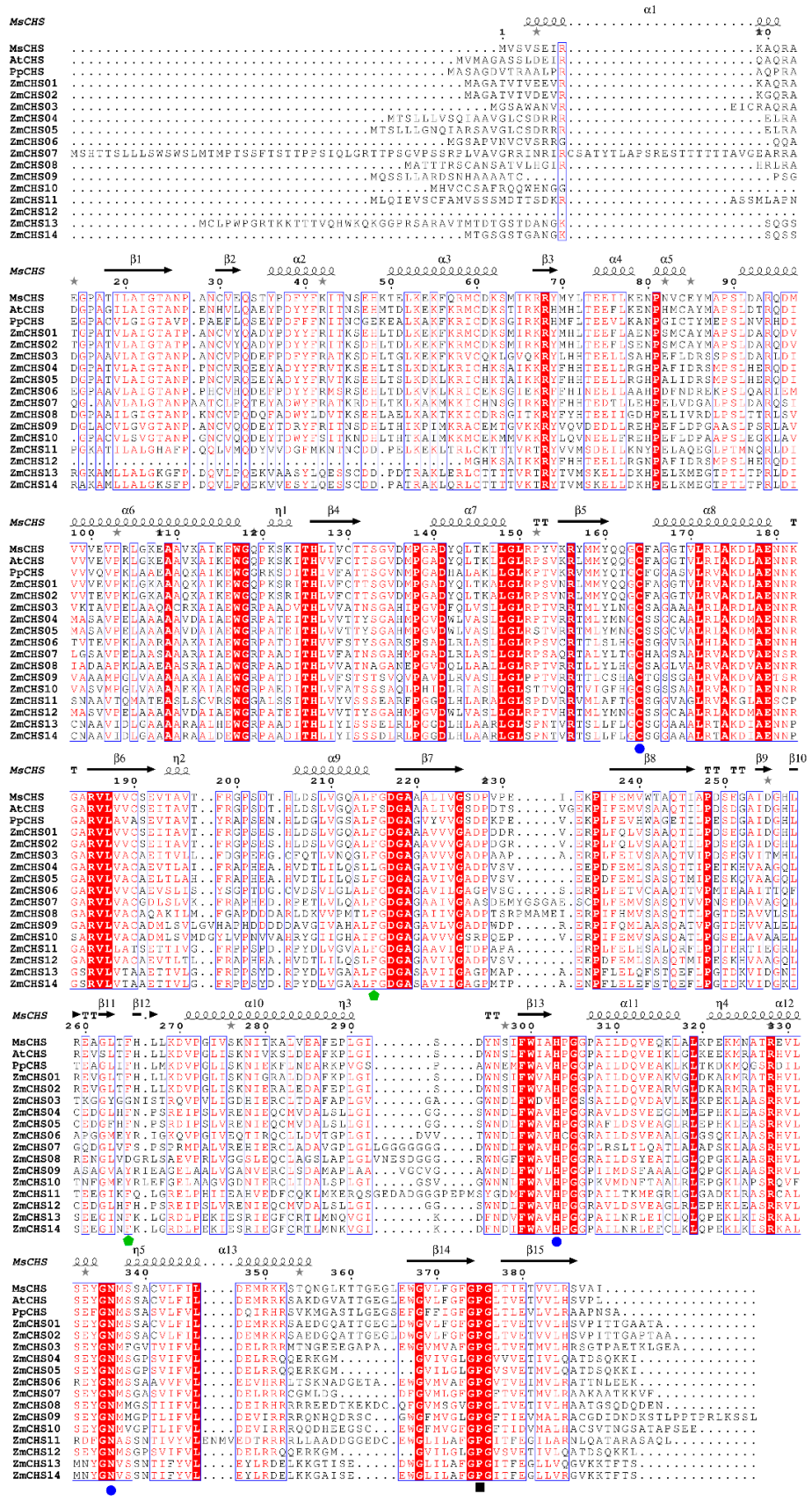

Figure 3. Sequence alignment of ZmCHSs against the other plant CHSs. The first line represents the secondary structure of Medicago sativa chalcone synthase (MsCHS). The blue boxes and red letters represent conserved residues. The red regions represent sequences of strict sequence conservation. The black wave lines and black arrows represent $\alpha$-helix and $\beta$-pleated sheet. The catalytic triad of CHSs, residues connected with CoA-binding and CHS family-specific Pro375 are labeled with blue points, green pentagrams and black quadrangles at the bottom of the sequences, respectively. MsCHS = Medicago sativa (alfalfa) chalcone synthase (P30074); AtCHS = Arabidopsis chalcone synthase (AAB35812.1); PpCHS = Physcomitrella patens chalcone synthase (ABB84527.1).

The "gatekeeper" phenylalanines connected with CoA-binding at positions 215 and 265 [3] are also conserved. The exceptions to these conservations are ZmCHSO4 which contains a lysine substituted for phenylalanine at position 215, and ZmCHS03, $-06,-08,-09$ and -10 which contain other amino acid residues substituted for phenylalanine at position 265 (Figure 3), which probably led to 
remarkable functional diversity, such as the choice of the initial substrates. The CHS family-specific Pro375 residues [3] were also maintained in all the ZmCHSs (Figure 3). The secondary structure of the putative maize CHS proteins was analyzed with the secondary structure of Medicago sativa chalcone synthase (MsCHS) as a template using online server PDB and ESpript. An alignment of MsCHS, ZmCHSs and other plant CHSs was also performed using the ClustalW software. All these results indicated that $\mathrm{ZmCHSs}$ exhibited high similarity in sequences with MsCHSs and other plant CHSs, suggesting that the CHS family is conserved during the evolutionary process (Figure 3).

\subsection{Chromosomal Location, Gene Duplication}

A physical map was drawn to show the distribution of $\mathrm{ZmCHSs}$ on different chromosomes of maize. The $14 \mathrm{ZmCHSs}$ were located unevenly on chromosome number 1, 2, 3, 4, 5 and 7 (Figure 4). Chromosome 4 contained the largest number of $\mathrm{ZmCHSs}$ (four) followed by chromosome 3 (three), and each of chromosomes 2, 5 and 7 contained two ZmCHS genes. Chromosomes 6, 8, 9 and 10 had no CHS genes.

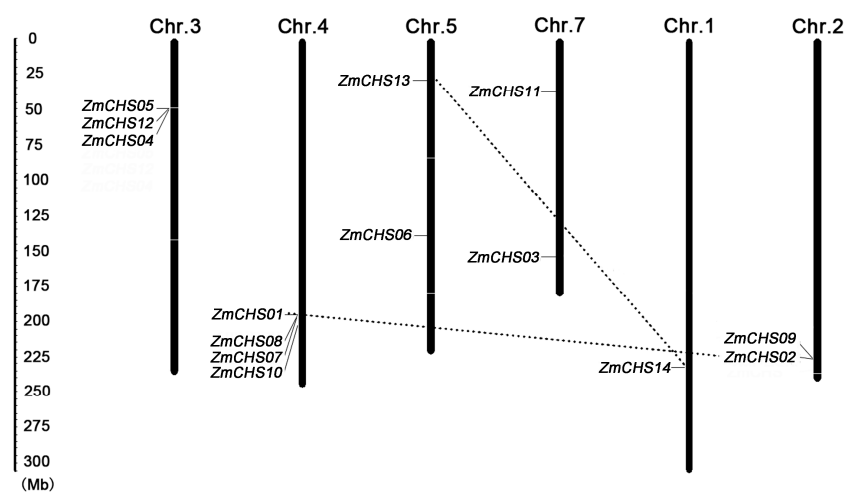

Figure 4. Location of 14 CHS genes on maize chromosomes. The "Chr." at the top of each bar represent the chromosome number of maize. The location of each CHS gene is indicated by corresponding gene name at the left of corresponding chromosome. The segmental duplicated genes are connected by dashed lines. The scale on the left is in megabases.

Gene duplication events, including tandem and segmental duplications, are considered as a driving force for the expansion of many gene families during the evolutionary process [33,34]. In this study, two gene pairs ( $\mathrm{ZmCHS01/02,} \mathrm{ZmCHS13/14)} \mathrm{were} \mathrm{found} \mathrm{to} \mathrm{be} \mathrm{involved} \mathrm{in} \mathrm{segmental}$ repeats (Figure 4). They shared a similar evolutionary process and were closely related to each other according to their phylogenetic relationships and gene structures (Figure 1). So the two gene pairs were considered as segmental duplications. In contrast, no tandem duplications occurred.

To explore the selective constraints among the two pairs of duplicated ZmCHS genes, their ratios of the number of nonsynonymous substitutions per non-synonymous site $(\mathrm{Ka})$ to the number of synonymous substitutions per synonymous site $(\mathrm{Ks})(\mathrm{Ka} / \mathrm{Ks})$ were calculated (Table 3$)$. In general, a $\mathrm{Ka} / \mathrm{Ks}$ ratio of $>1$ represents positive selection with promoted evolution; a ratio of 1 represents neutral selection and a ratio of $<1$ represents negative or purifying selection. In our study, $\mathrm{Ka} / \mathrm{Ks}$ ratios of the two pairs of duplicated CHS genes were $<1$, indicating that after the gene duplication events, these duplicated $\mathrm{ZmCHS}$ genes evolved under purifying selection with narrow functional divergence (Table 3, Figure 5). Because some positive selection might be shielded by strong purifying selection, a sliding-window analysis for each pair of duplicated $\mathrm{ZmCHS}$ genes was also carried out in order to obtain the $\mathrm{Ka} / \mathrm{Ks}$ ratios at different sites of coding sequences. The results suggested that $\mathrm{Ka} / \mathrm{Ks}$ ratios of the CHS conserved domains including Chal_sti_synt_C domain and Chal_sti_synt_N domain were $<1$, suggesting negative selection effect (Table 3, Figure 5). We speculated that purifying selection might have contributed for the maintenance of function in maize CHS family to some degree. 
Table 3. Ka/Ks analysis for the duplicated ZmCHS paralogs.

\begin{tabular}{ccccc}
\hline Duplicated Pairs & Ka & Ks & Ka/Ks & Purifying Selection \\
\hline ZmCHS01-ZmCHS02 & 0.015 & 0.155 & 0.095 & Yes \\
ZmCHS13-ZmCHS14 & 0.027 & 0.22 & 0.123 & Yes \\
\hline
\end{tabular}
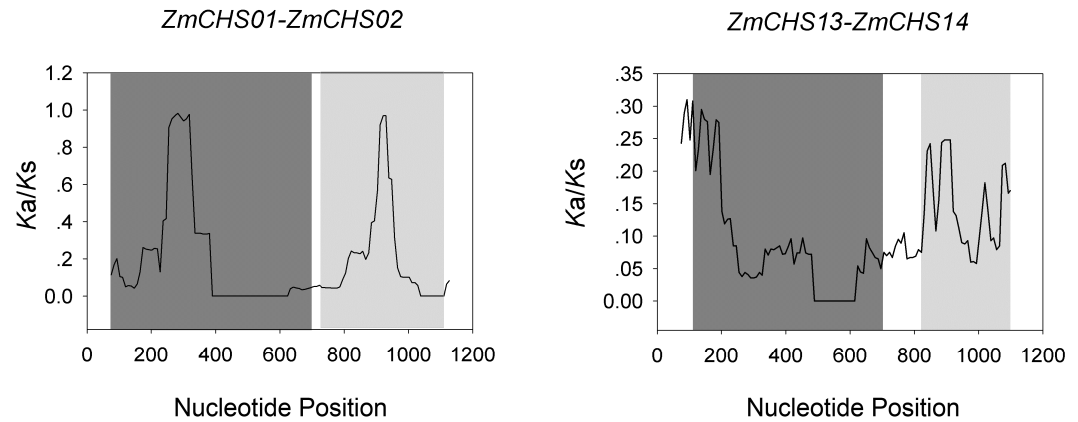

Figure 5. Sliding window plots of duplicated CHS genes. The gray blocks, from dark to light, indicate the positions of the Chal_sti_synt_N domain and Chal_sti_synt_C domain, respectively. The window size was $150 \mathrm{bp}$ and the step size was $9 \mathrm{bp}$.

\subsection{Microarray Analysis of CHS Expression during Maize Development}

The expression patterns of genes are usually related to their function. To obtain the expression patterns of maize CHS genes, the maize microarray data by Sekhon et al. [35] were downloaded and analysed. The expression patterns of the $14 \mathrm{ZmCHS}$ genes in diverse organs at different developmental stages were investigated by cluster expression profiles (Figure 6). The results revealed that the expression patterns of $\mathrm{CHS}$ genes were diverse. The majority of the $\mathrm{CHS}$ gene family members showed little expression in most maize tissues, including seeds, leaves, endosperm and embryo. The exceptions to this were $\mathrm{ZmCHS01/02,} \mathrm{which} \mathrm{showed} \mathrm{elevated} \mathrm{levels} \mathrm{of} \mathrm{constitutive} \mathrm{expression} \mathrm{in} \mathrm{seeds} \mathrm{and} \mathrm{all}$ stages of leaves development (Figure 6).

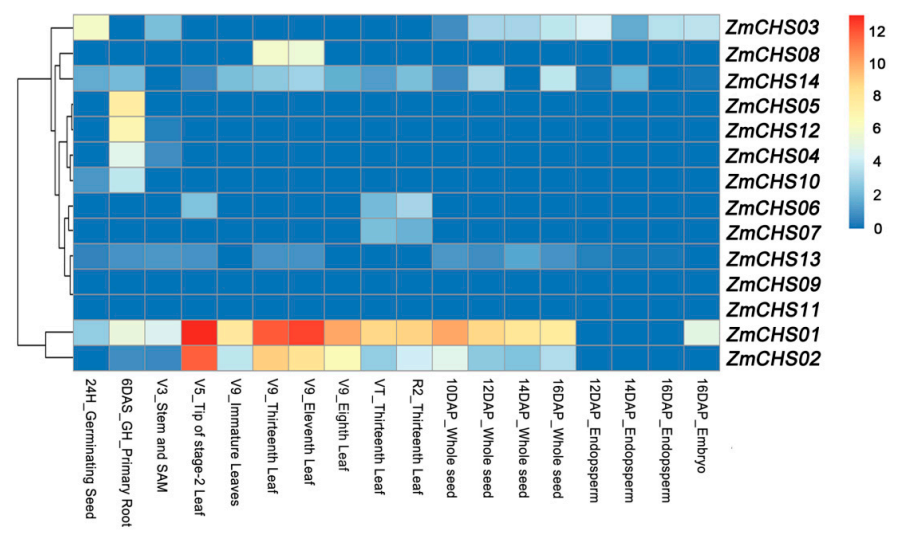

Figure 6. Clustering of expression profiles of $14 \mathrm{ZmCHS}$ genes. Different organs/tissues are exhibited below each column. 24H, $24 \mathrm{~h}$ after imbibition; DAS, days after sowing; GH, growth hormone; SAM, Shoot apical meristem; V3, Vegetative 3, three fully extended leaves; V5, Vegetative 5, five fully extended leaves; VT, Vegetative tasseling, last branch of the tassel fully emerged; R2, Reproductive 2, 10-14 days after silk emergence; DAP, days after pollination. The names of $\mathrm{ZmCHS}$ genes are displayed at the right side of each row. The colour box from blue to orange indicate an increased expression level. 


\subsection{Expression Levels of Maize CHS Genes in Response to Salicylic Acid Treatment}

Expression of the CHS genes can be stimulated by various biotic and abiotic elicitors including light, infection, mechanical wounding and plant hormones [36-38]. Therefore, we examined the expression levels of the $\mathrm{ZmCHSs}$ in response to abiotic stress by subjecting maize seedlings to salicylic acid. No expression was detected for four genes (ZmCHS04, -09, -10, -11); therefore, the remaining 10 maize $C H S$ genes were chosen for further qPCR analysis. The result revealed diverse expression patterns following salicylic acid treatment. As shown in Figure 7, the expression levels of the $10 \mathrm{ZmCHSs}$ were compared to untreated plants and were induced or repressed by this stress treatment, albeit some induction was slight. After salicylic acid treatment, the expressions of ZmCHS01, $-02,-03,-05,-07$ and -12 were highly induced at a relatively early stage ( $1 \mathrm{~h}$ after treatment), while expressions of $\mathrm{ZmCHS13}$ and -14 peaked at $6 \mathrm{~h}$ after treatment. We noted that the expression of $\mathrm{ZmCHS06}$ was down-regulated following salicylic acid treatment at all time points. Interestingly, the expression patterns of the segmental duplicated genes $(\mathrm{ZmCHS01/02)}$ displayed high similarity after salicylic acid treatment. Analogously, the expression patterns of the other segmental duplicated genes (ZmCHS13/14) exhibited similarity and both peaked at $6 \mathrm{~h}$ after treatment.
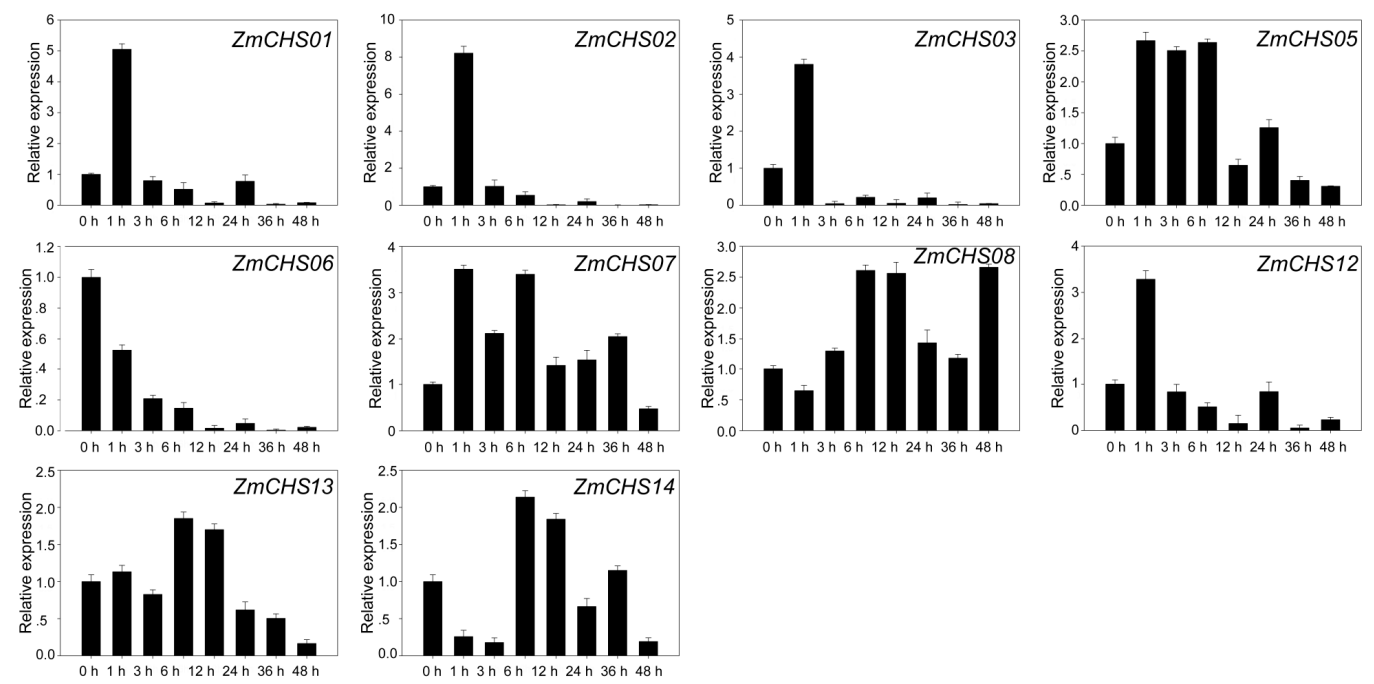

Figure 7. Expression patterns of $10 \mathrm{ZmCHS}$ genes after salicylic acid treatment. Relative expression levels of $\mathrm{ZmCHS}$ genes in response to salicylic acid were examined by qPCR and normalized by the expression of Maize Actin 1 (NM_001136991.1). The $y$-axis represents the relative expression level and the $x$-axis represents the time course of stress treatment. Seedlings were sampled at $0,1,3,6,12,24$, 36 and $48 \mathrm{~h}$ after salicylic acid treatment. There were three technical replicates for each of the three biological replicates.

\section{Discussion}

The CHS gene family plays important roles in the growth and development of plants. Most plant genomes contain smaller CHS gene families. For example, in Petunia hybrida, eight complete CHS genes and four partial genes have been cloned and sequenced [39,40]. Six CHS genes were identified in Ipomoea [41]. At least eight CHS members were identified in pea (Pisum sativum) [42]. In this study, 14 CHS genes were identified in maize, which is one of the largest numbers of CHS family members identified in one organism to date, and is approximately consistent with previously reported numbers (15 or more) [25]. It is considered that gene duplications have led to the wide expansion of the gene family during evolutionary process. The genome of maize has gone through several rounds of duplications early in its evolutionary progress $[43,44]$. Two segmental duplication events were found among the $14 \mathrm{ZmCHS}$ genes. Thus, around $29 \%$ of $\mathrm{ZmCHS}$ genes arose from the 
duplicated chromosomal regions. In contrast, no tandemly duplicated genes were found. These results suggested that segmental duplication was the dominating contributor for the expansion of maize CHS family. It was previously reported that there were 13 members encoding active CHS or CHS-like enzymes in physcomitrella patens CHS family [28], indicating that the ancient ancestors of plants already contained many $\mathrm{CHS}$ genes. So we speculated that a part of the 10 non-replicated $\mathrm{ZmCHS}$ genes might have arisen from the $C H S$ genes of the ancestor moss. In addition, two maize CHS genes (C2 and Whp), and one anther specific chalcone synthase-like (ASCL) gene (ZmCHSL, NP_001149508) were previously reported [22-24]. Analysis of the sequence alignment between the 14 genes and $C 2$, Whp and ZmCHSL (NP_001149508) were conducted, and the high identities allowed us to conclude that $\mathrm{ZmCHSO1}$ is $\mathrm{C2}$, and $\mathrm{ZmCHSO2}$ and $\mathrm{ZmCHS11}$ are likely to be Whp and ZmCHSL, respectively.

All ZmCHS genes could be broadly classified into four major classes: Classes I, II, III and IV based on their phylogenetic relationships. The motif distribution by Multiple Expectation Maximization for Motif Elicitation (MEME) was basically consistent with the phylogenetic analysis. The members in the same subfamily usually shared subfamily-specific conserved motifs. Furthermore, the two domains Chal_sti_synt_C and Chal_sti_synt_N, defined by motif distribution, were highly conserved in almost all of the $\mathrm{ZmCHS}$ genes, suggesting conserved evolution. Motifs 1 and 4 include the catalytic triad of $\mathrm{CHN}$ and are considered to be very important for the catalytic function. The catalytic triad inherited from the KAS III ancestor [3] are highly conserved in all of the ZmCHSs. There are some substitutes at positions Phe215 and Phe265, which are connected with CoA-binding [3]. These substitutions probably resulted in the different choice of the substrate. All the $\mathrm{ZmCHSs}$ contain the CHS family-specific Pro375 [3] (Figure 3), indicating the conserved evolution. Furthermore, the sequence alignment of the putative maize CHS proteins with MsCHS and other plant CHSs exhibited high similarity in sequences, suggesting that the CHS family are conserved in different species.

The gene structure analysis not only supported the phylogenetic analysis, but also revealed that the CHS genes were highly conserved during the evolutionary process of maize. In this study, most of the CHS genes (12 of 14) contained two exons and one intron, which was consistent with the previously proposed structure comprising two exons and one intron [45]. The gene duplication events also implied the conserved evolution of maize CHS genes. Previous studies suggested that the genome of maize has gone through several rounds of duplication. The duplication included an ancient genome duplication about 50-70 million years ago (Mya) when the grass genomes had not yet diverged, leading to the ancient tetraploid ancestry, another whole genome duplication approximately five Mya after the divergence of sorghum and maize and a recent duplication event [29,46-48]. In general, tandem duplications contribute to generate new genes [49]. However, segmental duplications tend to disperse gene copies [49], leading to them evolving slowly [33,50]. In this study, the presence of segmental duplications among the CHS genes indicates that this gene family is conserved and slowly evolving in maize.

Gene expression patterns are an important aspect of the study of gene function, and genes with similar expression patterns may have common features, be regulated by the same gene, or possess a common origin [51,52]. High-throughput microarray technology provides a good platform for the study of genome-wide gene expression patterns. The transcription profiles of maize revealed that the gene expression levels were highly diverse among tissues, with a variation ranging from $10 \%$ to $744 \%$ [35]. In this study, the majority of $Z m C H S$ gene family members showed little expression in most maize tissues, except for $\mathrm{ZmCHS01/02.} \mathrm{Most} \mathrm{ZmCHS}$ genes exhibited variable expression patterns, suggesting functional diversification of $\mathrm{ZmCHS}$ genes. In addition, along with multiple functions of CHSs, the expression of these genes might occur under specific environments or is specific to an organ or developmental stage. For example, the expression of certain $\mathrm{CHS}$ genes in plants is affected by methyl jasmonate (MeJA), abscisic acid (ABA), salicylic acid (SA) [30] and light [28]. Moreover, many genes exhibited similar expression patterns, which might in turn catalyze similar substrates in the same biochemical pathway. In conclusion, the expression profiling in this study provides an important basis for further studying of expression and biological functions of the CHS gene family in maize. 
The growth and development of plants is usually threatened by stresses from surroundings, such as drought, low temperature and high salinity during their life cycles. A lot of stress-related genes were induced to adapt to these environmental stresses [53,54]. The CHS family has been demonstrated to be regulated by salicylic acid treatment [30]. However, no CHS genes responding to salicylic acid stress have been reported in maize. Thus, we performed a survey of the expression patterns of the

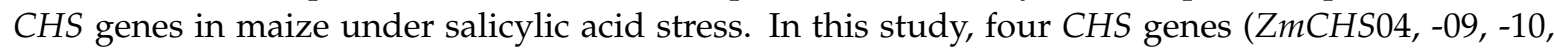
-11) showed no detectable expression, which was also clearly shown in the heat map. The expression patterns of the other 10 maize CHS genes were investigated under salicylic acid treatments. The results suggested that all ten genes were responsive to salicylic acid treatment. More than half of the genes were highly expressed at a relatively early stage $(1 \mathrm{~h}$ after treatment), and showed similar expression patterns. This indicated that these genes might execute their functions simultaneously. By contrast, the expression levels of a small number of genes peaked at six $\mathrm{h}$ after treatment, indicating that these genes are involved in a late-stage response to salicylic acid. In addition, the down-regulated gene $\mathrm{ZmCHSO6}$ might also have specific functions in maize under salicylic acid treatment, such as defense [55]. We hypothesized that most CHS genes play essential roles in response to abiotic stresses such as salicylic acid. This conclusion was supported by the close relationship of $\mathrm{ZmCHS}$ to PaCHS, whose expression was also increased after salicylic acid treatment [30]. These results indicated that most CHS genes were induced by salicylic acid and might contribute to the defense against abiotic stresses or disease resistance [55-57] in maize. We noted that the two pairs of duplicated genes, $\mathrm{ZmCHS01/02}$ and $\mathrm{ZmCHS13/14}$ had very similar expression patterns in response to salicylic acid treatment. This indicated that the duplicated genes might have redundant functions in response to the abiotic stress. In addition, the $\mathrm{Ka} / \mathrm{Ks}$ ratios of the two segmental duplication pairs were $<1$, indicating purifying selection, which confirmed our conclusion that the duplicated CHS genes mainly went through narrow functional divergence after duplication events.

In this study, we report our findings on the gene architecture, evolution and expression response to salicylic acid of the CHS genes in maize. In conclusion, the conservation and diversity of the CHS family genes make maize a model system for further studying of the functions, regulation and evolution of the CHS family.

\section{Materials and Methods}

\subsection{Identification and Sequence Analysis of CHS Proteins in Maize}

Firstly, we downloaded the complete gene sequences and protein sequences of maize from the database [58], and built a local database using the DNATOOLS software (Savita Shanker, FL, USA). We obtained the conserved domain sequences of the CHS family using Hidden Markov Model (HMM) while searching the Pfam [31]. Subsequently, this conserved domain sequences were employed to search for all CHS proteins in the local protein database using the BlastP program (Savita Shanker, FL, USA) ( $p$-value $=0.001$ ). Pfam and SMART [59] were then used to authenticate each CHS protein, which was key for the identification of the valid CHS proteins. We aligned all the candidate CHS sequences using ClustalW software (Kyoto University Bioinformatics Center, Kyoto, Japan) [60] and excluded potential redundant sequences. Finally the non-redundant $C H S$ genes were obtained for further analysis. In addition, we calculated the molecular mass (Da) and isoelectric point (pI) of every protein using ExPASy (SIB Swiss Institute of Bioinformatics, Lausanne, Switzerland).

\subsection{Phylogenetic Analysis}

Protein sequence alignment was performed using the Clustal X program (Des Higgins, DUB, Ireland). Then, phylogenetic tree was built using the NJ (neighbor-joining) method with bootstrap 1000 using MEGA 4.0 (Koichiro Tamura, TKY, Japan [61]. According to the phylogenetic relationships, we classified the $\mathrm{ZmCHS}$ genes into subfamilies. 


\subsection{Analysis of Conserved Motifs, Gene Structure and Sequence Alignment}

We investigated the conserved motifs in each putative ZmCHS protein using the MEME web sever [62]. The following parameters were set: width of motif is $\geqslant 6$ and $\leqslant 200$ and maximum number of motifs to find is 20. In addition, the gene structure analysis, including exon and intron, was performed by comparing the gene sequences with the predicted coding sequences using Gene Structure Display Server (GSDS) [63].

The crystal structure of alfalfa CHS [64] has revealed the configuration of amino acid residues in many active sites. Studies on the structure and function of the MsCHS protein have been thorough and comprehensive. So we used the secondary structure of $\mathrm{MsCHS}$ as a template to analyze the secondary structures of maize CHSs using the online server Protein Data Bank (PDB) [65] and ESpript [66]. An alignment of alfalfa CHS, ZmCHSs and other plant CHS proteins was performed using the ClustalW software (Kyoto University Bioinformatics Center, Kyoto, Japan).

\subsection{Chromosomal Locations and Gene Duplication}

The physical map of the ZmCHS genes was drawn by using MapInspect [67], according to their positions on the chromosomes of maize. The MCScan software [68] was used to identify the duplicated $\mathrm{ZmCHS}$ genes. The maize whole-genome sequences were downloaded to our local server and were analyzed using an all-versus-all Basic Local Alignment Search Tool (BLAST) search with an E-value less than $1 \times 10^{-5}$. Subsequently, the MCScan software was used to analyze the synteny regions [68]. The pairs of genes located in these duplicated regions were considered as segmental duplication gene pairs and were indicated on the physical map.

\subsection{Microarray Analysis of CHSs in Maize}

Publically available transcriptome data by Sekhon et al. [35] were obtained to examine the expression patterns of $\mathrm{ZmCHS}$ genes. The gene expression patterns in roots, seeds, leaves, endosperm and embryo were drawn using R/Bioconductor [69].

\subsection{Plant Material and Salicylic Acid Stress Treatment}

To measure the expression levels of CHS genes under abiotic stress, the seeds of maize inbred line B73 were grown in the greenhouse at $28 \pm 2{ }^{\circ} \mathrm{C}$ with a $14 \mathrm{~h}$ light $/ 10 \mathrm{~h}$ dark photoperiod. After three weeks, the leaves of the maize (five-leaf stage seedlings) were sprayed with $100 \mathrm{mM}$ salicylic acid solution and sampled at $0,1,3,6,12,24,36$ and $48 \mathrm{~h}$ after treatment. There are three biological replicates for each sample.

\subsection{RNA Isolation and Quantitative Real-Time PCR (qPCR) Analysis}

The leaves of the maize seedlings sprayed with salicylic acid solution were sampled at $0,1,3,6$, $12,24,36$ and $48 \mathrm{~h}$ after treatment for RNA isolation. Total RNA was extracted according to the CTAB method [70]. Then DNaseI (Invitrogen, Shanghai, China) was used to remove residual DNA, followed by reverse-transcription using Moloney Murine Leukemia Virus (M-MLV) reverse transcriptase (Invitrogen, Shanghai, China). The ABI 7300 Real-Time system (Applied Biosystems, Foster, CA, USA) was used to perform the qPCR (quantitative real-time PCR). Primer Express 3.0 software (Applied Biosystems, Foster, CA, USA) was used to design the specific primers for amplifying each $\mathrm{ZmCHS}$ gene (Table S1). Each reaction contained a system of $20 \mu \mathrm{L}$ including $12.5 \mu \mathrm{L}$ of SYBR Green Master Mix reagent (Applied Biosystems), $400 \mathrm{nM}$ specific primers and $1.5 \mu \mathrm{L}$ of cDNA. The qPCR reaction conditions were set as follows: $95^{\circ} \mathrm{C}$ for $10 \mathrm{~min}$; followed by 40 cycles at $95^{\circ} \mathrm{C}$ for $15 \mathrm{~s}$ and $60^{\circ} \mathrm{C}$ for $1 \mathrm{~min}$. Subsequently, a melting curve was formed to check the specificity of the genes. The qPCR was carried out with three technical replicates for each of the three biological replicates. The expression level of the maize Actin 1 gene was treated as an internal reference. The relative expression level of each gene was calculated as $2^{-\Delta \Delta C t}\left[\Delta C_{t}=C_{t, \text { Target }}-C_{\mathrm{t}, \text { Actin } 1} ; \Delta \Delta C_{t}=\Delta C_{\mathrm{t}, \text { treatment }}-\Delta C_{\mathrm{t}, \mathrm{CK}(0 \mathrm{~h})}\right]$ [71]. 
Supplementary Materials: Supplementary materials can be found at http:/ /www.mdpi.com/1422-0067/17/ 2/161/s1.

Acknowledgments: This work was supported by the National Natural Science Foundation of China (31371980, 31301324) and the Key Science and Technology Program of Anhui Province (15czz03119). We extend our thanks to Asif Ali for his careful reading and helpful comments on this manuscript.

Author Contributions: All authors worked collaboratively on all aspects of the manuscript.

Conflicts of Interest: The authors declare no conflict of interest.

\section{References}

1. Martinez-Perez, C.; Ward, C.; Cook, G.; Mullen, P.; McPhail, D.; Harrison, D.J.; Langdon, S.P. Novel flavonoids as anti-cancer agents: Mechanisms of action and promise for their potential application in breast cancer. Biochem. Soc. Trans. 2014, 42, 1017-1023. [CrossRef] [PubMed]

2. Jiang, C.; Kim, S.Y.; Suh, D.-Y. Divergent evolution of the thiolase superfamily and chalcone synthase family. Mol. Phylogenet. Evol. 2008, 49, 691-701. [CrossRef] [PubMed]

3. Austin, M.B.; Noel, J.P. The chalcone synthase superfamily of type III polyketide synthases. Nat. Prod. Rep. 2003, 20, 79-110. [CrossRef] [PubMed]

4. Schröder, J. A family of plant-specific polyketide synthases: Facts and predictions. Trends Plant Sci. 1997, 2, 373-378. [CrossRef]

5. Liu, B.; Raeth, T.; Beuerle, T.; Beerhues, L. Biphenyl synthase, a novel type III polyketide synthase. Planta 2007, 225, 1495-1503. [CrossRef] [PubMed]

6. Jez, J.M.; Austin, M.B.; Ferrer, J.-L.; Bowman, M.E.; Schröder, J.; Noel, J.P. Structural control of polyketide formation in plant-specific polyketide synthases. Chem. Biol. 2000, 7, 919-930. [CrossRef]

7. Lu, H.; Yang, M.; Liu, C.; Lu, P.; Cang, H.; Ma, L. Protein preparation, crystallization and preliminary X-ray analysis of polygonum cuspidatum bifunctional chalcone synthase/benzalacetone synthase. Acta Crystallogr. Sect. F Struct. Biol. Cryst. Commun. 2013, 69, 871-875. [CrossRef] [PubMed]

8. Parage, C.; Tavares, R.; Réty, S.; Baltenweck-Guyot, R.; Poutaraud, A.; Renault, L.; Heintz, D.; Lugan, R.; Marais, G.A.; Aubourg, S. Structural, functional, and evolutionary analysis of the unusually large stilbene synthase gene family in grapevine. Plant Physiol. 2012, 160, 1407-1419. [CrossRef] [PubMed]

9. Han, Y.-Y.; Ming, F.; Wang, W.; Wang, J.-W.; Ye, M.-M.; Shen, D.-L. Molecular evolution and functional specialization of chalcone synthase superfamily from phalaenopsis orchid. Genetica 2006, 128, 429-438. [CrossRef] [PubMed]

10. Huang, L.; Wang, H.; Ye, H.; Du, Z.; Zhang, Y.; Beerhues, L.; Liu, B. Differential expression of benzophenone synthase and chalcone synthase in hypericum sampsonii. Nat. Prod. Commun. 2012, 7, 1615-1618. [PubMed]

11. Morita, H.; Kondo, S.; Oguro, S.; Noguchi, H.; Sugio, S.; Abe, I.; Kohno, T. Structural insight into chain-length control and product specificity of pentaketide chromone synthase from aloe arborescens. Chem. Biol. 2007, 14, 359-369. [CrossRef] [PubMed]

12. Watanabe, K.; Praseuth, A.P.; Wang, C.C. A comprehensive and engaging overview of the type III family of polyketide synthases. Curr. Opin. Chem. Biol. 2007, 11, 279-286. [CrossRef] [PubMed]

13. Akiyama, T.; Shibuya, M.; Liu, H.M.; Ebizuka, Y. p-Coumaroyltriacetic acid synthase, a new homologue of chalcone synthase, from Hydrangea macrophylla var. Thunbergii. Eur. J. Biochem. 1999, 263, 834-839. [CrossRef] [PubMed]

14. Eckermann, S.; Schröder, G.; Schmidt, J.; Strack, D.; Edrada, R.A.; Helariutta, Y.; Elomaa, P.; Kotilainen, M.; Kilpeläinen, I.; Proksch, P. New pathway to polyketides in plants. Nature 1998, 396, 387-390. [CrossRef]

15. Harris, N.; Luczo, J.; Robinson, S.; Walker, A. Transcriptional regulation of the three grapevine chalcone synthase genes and their role in flavonoid synthesis in shiraz. Aust. J. Grape Wine Res. 2013, 19, 221-229. [CrossRef]

16. Deng, X.; Bashandy, H.; Ainasoja, M.; Kontturi, J.; Pietiäinen, M.; Laitinen, R.A.; Albert, V.A.; Valkonen, J.; Elomaa, P.; Teeri, T.H. Functional diversification of duplicated chalcone synthase genes in anthocyanin biosynthesis of gerbera hybrida. New Phytol. 2014, 201, 1469-1483. [CrossRef] [PubMed]

17. Dare, A.P.; Tomes, S.; Jones, M.; McGhie, T.K.; Stevenson, D.E.; Johnson, R.A.; Greenwood, D.R.; Hellens, R.P. Phenotypic changes associated with rna interference silencing of chalcone synthase in apple (Malus $\times$ domestica). Plant J. 2013, 74, 398-410. [CrossRef] [PubMed] 
18. Liu, X.-J.; Chuang, Y.-N.; Chiou, C.-Y.; Chin, D.-C.; Shen, F.-Q.; Yeh, K.-W. Methylation effect on chalcone synthase gene expression determines anthocyanin pigmentation in floral tissues of two oncidium orchid cultivars. Planta 2012, 236, 401-409. [CrossRef] [PubMed]

19. Feinbaum, R.; Ausubel, F. Transcriptional regulation of the Arabidopsis thaliana chalcone synthase gene. Mol. Cell. Biol. 1988, 8, 1985-1992. [CrossRef] [PubMed]

20. Van der Meer, I.M.; Spelt, C.E.; Mol, J.N.; Stuitje, A.R. Promoter analysis of the chalcone synthase (chsA) gene of Petunia hybrida: A 67 bp promoter region directs flower-specific expression. Plant Mol. Biol. 1990, 15, 95-109. [CrossRef] [PubMed]

21. Schmid, J.; Doerner, P.W.; Clouse, S.D.; Dixon, R.A.; Lamb, C.J. Developmental and environmental regulation of a bean chalcone synthase promoter in transgenic tobacco. Plant Cell Online 1990, 2, 619-631. [CrossRef] [PubMed]

22. Della Vedova, C.B.; Lorbiecke, R.; Kirsch, H.; Schulte, M.B.; Scheets, K.; Borchert, L.M.; Scheffler, B.E.; Wienand, U.; Cone, K.C.; Birchler, J.A. The dominant inhibitory chalcone synthase allele C2-Idf (Inhibitor diffuse) from Zea mays (L.) acts via an endogenous RNA silencing mechanism. Genetics 2005, 170, 1989-2002. [CrossRef] [PubMed]

23. Franken, P.; Niesbach-Klösgen, U.; Weydemann, U.; Marechal-Drouard, L.; Saedler, H.; Wienand, U. The duplicated chalcone synthase genes $C 2$ and Whp (white pollen) of Zea mays are independently regulated; evidence for translational control of Whp expression by the anthocyanin intensifying gene in. EMBO J. 1991, 10, 2605-2612. [PubMed]

24. Jepson, C.; Karppinen, K.; Daku, R.M.; Sterenberg, B.T.; Suh, D.Y. Hypericum perforatum hydroxyalkylpyrone synthase involved in sporopollenin biosynthesis-phylogeny, site-directed mutagenesis, and expression in nonanther tissues. FEBS J. 2014, 281, 3855-3868. [CrossRef] [PubMed]

25. Wienand, U.; Weydemann, U.; Niesbach-Klösgen, U.; Peterson, P.A.; Saedler, H. Molecular cloning of the C2 locus of Zea mays, the gene coding for chalcone synthase. Mol. Gen. Genet. MGG 1986, 203, 202-207. [CrossRef]

26. Dooner, H.K.; Nelson, O.E. Interaction among $C, R$ and $V p$ in the control of the $B z$ glucosyltransferase during endosperm development in maize. Genetics 1979, 91, 309-315. [PubMed]

27. Dooner, H.K. Coordinate genetic regulation of flavonoid biosynthetic enzymes in maize. Mol. Gen. Genet. MGG 1983, 189, 136-141. [CrossRef]

28. Koduri, P.H.; Gordon, G.S.; Barker, E.I.; Colpitts, C.C.; Ashton, N.W.; Suh, D.-Y. Genome-wide analysis of the chalcone synthase superfamily genes of physcomitrella patens. Plant Mol. Biol. 2010, 72, 247-263. [CrossRef] [PubMed]

29. Schnable, P.S.; Ware, D.; Fulton, R.S.; Stein, J.C.; Wei, F.; Pasternak, S.; Liang, C.; Zhang, J.; Fulton, L.; Graves, T.A. The B73 maize genome: Complexity, diversity, and dynamics. Science 2009, 326, 1112-1115. [CrossRef] [PubMed]

30. Yu, H.-N.; Wang, L.; Sun, B.; Gao, S.; Cheng, A.-X.; Lou, H.-X. Functional characterization of a chalcone synthase from the liverwort plagiochasma appendiculatum. Plant Cell Rep. 2015, 34, 233-245. [CrossRef] [PubMed]

31. Finn, R.D.; Mistry, J.; Schuster-Böckler, B.; Griffiths-Jones, S.; Hollich, V.; Lassmann, T.; Moxon, S.; Marshall, M.; Khanna, A.; Durbin, R. Pfam: Clans, web tools and services. Nucleic Acids Res. 2006, 34, D247-D251. [CrossRef] [PubMed]

32. Götz, S.; García-Gómez, J.M.; Terol, J.; Williams, T.D.; Nagaraj, S.H.; Nueda, M.J.; Robles, M.; Talón, M.; Dopazo, J.; Conesa, A. High-throughput functional annotation and data mining with the Blast2GO suite. Nucleic Acids Res. 2008, 36, 3420-3435. [CrossRef] [PubMed]

33. Cannon, S.B.; Mitra, A.; Baumgarten, A.; Young, N.D.; May, G. The roles of segmental and tandem gene duplication in the evolution of large gene families in Arabidopsis thaliana. BMC Plant Biol. 2004, 4. [CrossRef] [PubMed]

34. Mehan, M.R.; Freimer, N.B.; Ophoff, R.A. A genome-wide survey of segmental duplications that mediate common human genetic variation of chromosomal architecture. Hum. Genom. 2004, 1. [CrossRef]

35. Sekhon, R.S.; Lin, H.; Childs, K.L.; Hansey, C.N.; Buell, C.R.; de Leon, N.; Kaeppler, S.M. Genome-wide atlas of transcription during maize development. Plant J. 2011, 66, 553-563. [CrossRef] [PubMed]

36. Harashima, S.; Takano, H.; Ono, K.; Takio, S. Chalcone synthase-like gene in the liverwort, Marchantia paleacea var. diptera. Plant Cell Rep. 2004, 23, 167-173. [CrossRef] [PubMed] 
37. Jeong, S.T.; Goto-Yamamoto, N.; Kobayashi, S.; Esaka, M. Effects of plant hormones and shading on the accumulation of anthocyanins and the expression of anthocyanin biosynthetic genes in grape berry skins. Plant Sci. 2004, 167, 247-252. [CrossRef]

38. Junghans, H.; Dalkin, K.; Dixon, R.A. Stress responses in alfalfa (Medicago sativa L.). 15. Characterization and expression patterns of members of a subset of the chalcone synthase multigene family. Plant Mol. Biol. 1993, 22, 239-253. [CrossRef] [PubMed]

39. Koes, R.E.; Spelt, C.E.; Mol, J.N. The chalcone synthase multigene family of Petunia hybrida (V30): Differential, light-regulated expression during flower development and UV light induction. Plant Mol. Biol. 1989, 12, 213-225. [CrossRef] [PubMed]

40. Koes, R.E.; Spelt, C.E.; van den Elzen, P.J.; Mol, J.N. Cloning and molecular characterization of the chalcone synthase multigene family of petunia hybrida. Gene 1989, 81, 245-257. [CrossRef]

41. Durbin, M.L.; McCaig, B.; Clegg, M.T. Molecular evolution of the chalcone synthase multigene family in the morning glory genome. In Plant Molecular Evolution; Springer: Riverside, CA, USA, 2000; pp. 79-92.

42. Ito, M.; Ichinose, Y.; Kato, H.; Shiraishi, T.; Yamada, T. Molecular evolution and functional relevance of the chalcone synthase genes of pea. Mol. Gen. Genet. MGG 1997, 255, 28-37. [CrossRef] [PubMed]

43. Paterson, A.; Bowers, J.; Chapman, B. Ancient polyploidization predating divergence of the cereals, and its consequences for comparative genomics. Proc. Natl. Acad. Sci. USA 2004, 101, 9903-9908. [CrossRef] [PubMed]

44. Swigoňová, Z.; Lai, J.; Ma, J.; Ramakrishna, W.; Llaca, V.; Bennetzen, J.L.; Messing, J. Close split of sorghum and maize genome progenitors. Genome Res. 2004, 14, 1916-1923. [CrossRef] [PubMed]

45. Pang, Y.; Shen, G.; Wu, W.; Liu, X.; Lin, J.; Tan, F.; Sun, X.; Tang, K. Characterization and expression of chalcone synthase gene from Ginkgo biloba. Plant Sci. 2005, 168, 1525-1531. [CrossRef]

46. Wei, F.; Coe, E.; Nelson, W.; Bharti, A.K.; Engler, F.; Butler, E.; Kim, H.; Goicoechea, J.L.; Chen, M.; Lee, S. Physical and genetic structure of the maize genome reflects its complex evolutionary history. PLoS Genet. 2007, 3, e123. [CrossRef] [PubMed]

47. Salse, J.; Bolot, S.; Throude, M.; Jouffe, V.; Piegu, B.; Quraishi, U.M.; Calcagno, T.; Cooke, R.; Delseny, M.; Feuillet, C. Identification and characterization of shared duplications between rice and wheat provide new insight into grass genome evolution. Plant Cell Online 2008, 20, 11-24. [CrossRef] [PubMed]

48. Murat, F.; Xu, J.-H.; Tannier, E.; Abrouk, M.; Guilhot, N.; Pont, C.; Messing, J.; Salse, J. Ancestral grass karyotype reconstruction unravels new mechanisms of genome shuffling as a source of plant evolution. Genome Res. 2010, 20, 1545-1557. [CrossRef] [PubMed]

49. Baumgarten, A.; Cannon, S.; Spangler, R.; May, G. Genome-level evolution of resistance genes in Arabidopsis thaliana. Genetics 2003, 165, 309-319. [PubMed]

50. Jiang, C.; Gu, X.; Peterson, T. Identification of conserved gene structures and carboxy-terminal motifs in the Myb gene family of Arabidopsis and Oryza sativa L. ssp. Indica. Genome Biol. 2004, 5. [CrossRef]

51. Oakley, T.H.; Østman, B.; Wilson, A.C. Repression and loss of gene expression outpaces activation and gain in recently duplicated fly genes. Proc. Natl. Acad. Sci. USA 2006, 103, 11637-11641. [CrossRef] [PubMed]

52. Gu, X. Statistical framework for phylogenomic analysis of gene family expression profiles. Genetics 2004, 167, 531-542. [CrossRef] [PubMed]

53. Albrecht, V.; Weinl, S.; Blazevic, D.; D’Angelo, C.; Batistic, O.; Kolukisaoglu, Ü.; Bock, R.; Schulz, B.; Harter, K.; Kudla, J. The calcium sensor CBL1 integrates plant responses to abiotic stresses. Plant J. 2003, 36, 457-470. [CrossRef] [PubMed]

54. Kasuga, M.; Liu, Q.; Miura, S.; Yamaguchi-Shinozaki, K.; Shinozaki, K. Improving plant drought, salt, and freezing tolerance by gene transfer of a single stress-inducible transcription factor. Nat. Biotechnol. 1999, 17, 287-291. [PubMed]

55. Coram, T.E.; Pang, E.C. Transcriptional profiling of chickpea genes differentially regulated by salicylic acid, methyl jasmonate and aminocyclopropane carboxylic acid to reveal pathways of defence-related gene regulation. Funct. Plant Biol. 2007, 34, 52-64. [CrossRef]

56. Duan, Y.; Jiang, Y.; Ye, S.; Karim, A.; Ling, Z.; He, Y.; Yang, S.; Luo, K. PtrWRKY73, a salicylic acid-inducible poplar WRKY transcription factor, is involved in disease resistance in Arabidopsis thaliana. Plant Cell Rep. 2015, 34, 831-841. [CrossRef] [PubMed] 
57. Häffner, E.; Karlovsky, P.; Splivallo, R.; Traczewska, A.; Diederichsen, E. ERECTA, salicylic acid, abscisic acid, and jasmonic acid modulate quantitative disease resistance of Arabidopsis thaliana to Verticillium longisporum. BMC Plant Biol. 2014, 14. [CrossRef] [PubMed]

58. Goodstein, D.M.; Shu, S.; Howson, R.; Neupane, R.; Hayes, R.D.; Fazo, J.; Mitros, T.; Dirks, W.; Hellsten, U.; Putnam, N. Phytozome: A comparative platform for green plant genomics. Nucleic Acids Res. 2012, 40, D1178-D1186. [CrossRef] [PubMed]

59. Letunic, I.; Doerks, T.; Bork, P. Smart 6: Recent updates and new developments. Nucleic Acids Res. 2009, 37, D229-D232. [CrossRef] [PubMed]

60. Thompson, J.D.; Higgins, D.G.; Gibson, T.J. Clustal w: Improving the sensitivity of progressive multiple sequence alignment through sequence weighting, position-specific gap penalties and weight matrix choice. Nucleic Acids Res. 1994, 22, 4673-4680. [CrossRef] [PubMed]

61. Tamura, K.; Dudley, J.; Nei, M.; Kumar, S. MEGA4: Molecular evolutionary genetics analysis (MEGA) software version 4.0. Mol. Biol. Evol. 2007, 24, 1596-1599. [CrossRef] [PubMed]

62. Bailey, T.L.; Elkan, C. The Value of Prior Knowledge in Discovering Motifs with Meme; Ismb: La Jolla, CA, USA, 1995; pp. 21-29.

63. Guo, A.; Zhu, Q.; Chen, X.; Luo, J. GSDS: A gene structure display server. Yi chuan = Hereditas/Zhongguo Yi Chuan Xue Hui Bian Ji 2007, 29, 1023-1026. [CrossRef] [PubMed]

64. Ferrer, J.-L.; Jez, J.M.; Bowman, M.E.; Dixon, R.A.; Noel, J.P. Structure of chalcone synthase and the molecular basis of plant polyketide biosynthesis. Nat. Struct. Mol. Biol. 1999, 6, 775-784.

65. Berman, H.; Henrick, K.; Nakamura, H.; Markley, J.L. The worldwide Protein Data Bank (wwPDB): Ensuring a single, uniform archive of PDB data. Nucleic Acids Res. 2007, 35, D301-D303. [CrossRef] [PubMed]

66. Robert, X.; Gouet, P. Deciphering key features in protein structures with the new endscript server. Nucleic Acids Res. 2014, 42, W320-W324. [CrossRef] [PubMed]

67. MapInspect. Available online: http://www.softsea.com/review/MapInspect.html (accessed on 5 September 2015).

68. Tang, H.; Bowers, J.E.; Wang, X.; Ming, R.; Alam, M.; Paterson, A.H. Synteny and collinearity in plant genomes. Science 2008, 320, 486-488. [CrossRef] [PubMed]

69. Gentleman, R.C.; Carey, V.J.; Bates, D.M.; Bolstad, B.; Dettling, M.; Dudoit, S.; Ellis, B.; Gautier, L.; Ge, Y.; Gentry, J. Bioconductor: Open software development for computational biology and bioinformatics. Genome Biol. 2004, 5. [CrossRef] [PubMed]

70. Gasic, K.; Hernandez, A.; Korban, S.S. RNA extraction from different apple tissues rich in polyphenols and polysaccharides for cDNA library construction. Plant Mol. Biol. Rep. 2004, 22, 437-438. [CrossRef]

71. Livak, K.J.; Schmittgen, T.D. Analysis of relative gene expression data using real-time quantitative PCR and the $2^{-\Delta \Delta C t}$ method. Methods 2001, 25, 402-408. [CrossRef] [PubMed]

(C) 2016 by the authors; licensee MDPI, Basel, Switzerland. This article is an open access article distributed under the terms and conditions of the Creative Commons by Attribution (CC-BY) license (http:/ / creativecommons.org/licenses/by/4.0/). 